\title{
EMPOWERING DIGITAL BUSINESS BAGI PEGIAT USAHA ONLINE KOTA MALANG
}

\author{
Agus Purnomo Sidi ${ }^{1}$, Ahmad Nizar Yogatama ${ }^{2}$, M. Bukhori ${ }^{3}$, Rifki Hanif ${ }^{4}$, Widiya \\ Dewi Anjaningrum ${ }^{5}$ \\ 1,2,3,4,5 Institut Teknologi dan Bisnis Asia Malang \\ ${ }^{*}$ Coressponding author \\ E-mail: rifki.hanif@asia.ac.id (Rifki Hanif)*
}

Article History:

Received: 22-6-2020

Revised: 21-7-2020

Accepted: 3-8-2020

\section{Keywords:}

\section{Pendahuluan}

Persaingan hidup di era globalisasi yang semakin tinggi menjadikan setiap orang harus menjadi pribadi yang kreatif dan inovatif jika ingin merebut setiap peluang yang ada. Selain itu, tanpa mental yang kuat dan potensi mempraktikan setiap teori yang diperoleh dari dunia pendidikan seseorang tidak akan mampu bertahan. Lebih lagi, jumlah lapangan kerja yang terbatas, timpang dengan jumlah pencari kerja. Banyak orang terdidik, lulusan SMA, sarjana maupun pascasarjana yang menjadi pengangguran.

Jumlah wirausaha di Indonesia juga masih minim, hanya sekitar $0,18 \%$ dari total penduduk, padahal negara dikatakan maju jika negara tersebut memiliki wirausaha minimum $2 \%$ dari total penduduk. Saat ini ekonomi kreatif menjadi pusat perhatian tersendiri bagi pemerintah, karena sektor ini terbukti mampu menyumbang GDP yang cukup besar dengan pertumbuhan yang signifikan, hampir $10 \%$ tiap tahun. Kota Malang merupakan salah satu kota yang memiliki potensi besar untuk menjadi kota kreatif terkemuka. Ini dilandasi oleh terus bertambahnya startup industri kreatif.

\begin{abstract}
Untuk memulai bisnis di era digital, setiap pelaku digital seperti sekarang ini. Cara efektif yang dapat dilakukan adalah melalui pemasaran inbound. Kegiatan pengabdian bisnis online di Malang, khususnya para wirausahawan yang memiliki usaha baru untuk mengelola pemasaran online secara Digital untuk Aktivis Bisnis Online di Malang dilakukan dalam bentuk tutorial yang disampaikan langsung oleh pembicara. dimana berdasarkan hasil dedikasi ini, para aktivis bisnis online dalam kegiatan serupa untuk pengembangan pengetahuan disnis.

Digital Business, Inbound Marketing, Online, Malang
\end{abstract}


Untuk memulai bisnis di era digital, tentu setiap pelaku bisnis harus mampu memahami cara memasarkan di era digital seperti saat ini. Cara efektif yang bisa dilakukan adalah melalui inbound marketing. Oleh karena itu dalam pengabdian masyarakat ini akan dilakukan pelatihan Empowering Digital Business bagi Pegiat Usaha Online di Kota Malang.

\section{Metode}

Kegiatan Pelatihan Empowering Digital Business bagi Pegiat Usaha Online di Kota Malang dilakukan dalam bentuk tutorial yang disampaikan secara langsung oleh pemateri. Pelatihan ini dilaksanakan setiap hari sabtu dimulai pada tanggal 23 November 2019 pk. 13.00 s/d 15.00 di Institut Teknologi dan Bisnis Asia Malang di J. Soekarno Hatta-Rembuksari No. 1A. Pemberi materi adalah salah satu karyawan PT. Telkomsel bidang pemasaran. Bersedianya pihak Telkomsel memberikan pelatihan kepada masyarakat karena pelatihan ini telah menjadi kegiatan CSR Telkomsel selama beberapa tahun terakhir. Sementara sasaran pelatihan ini adalah kalangan anak muda yang memang sudah memiliki usaha atau sedang merintis usaha, kebanyakan mereka berstatus mahasiswa atau bahkan karyawan. Tema "Inbound Marketing" dipilih karena dianggap sesuai dengan kondisi menuntut usaha lebih dalam memenangi persaingan ataupun mendapatkan ceruk pasar yang sesuai bagi peserta pelatihan. Detail pelatihan dapat dilihat pada Gambar 1, Gambar 2 dan Gambar 3.

\section{Gambar 1}

\section{Penjelasan Tentang Inbound Marketing}

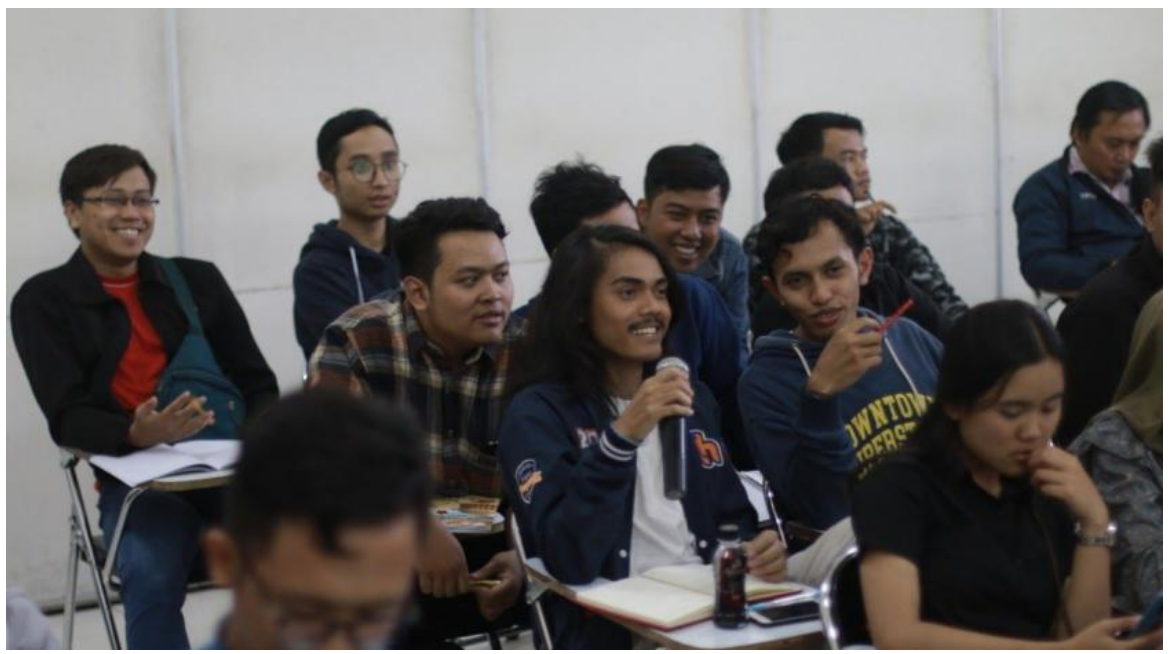




\section{Gambar 2}

\section{Praktik Inbound Marketing}

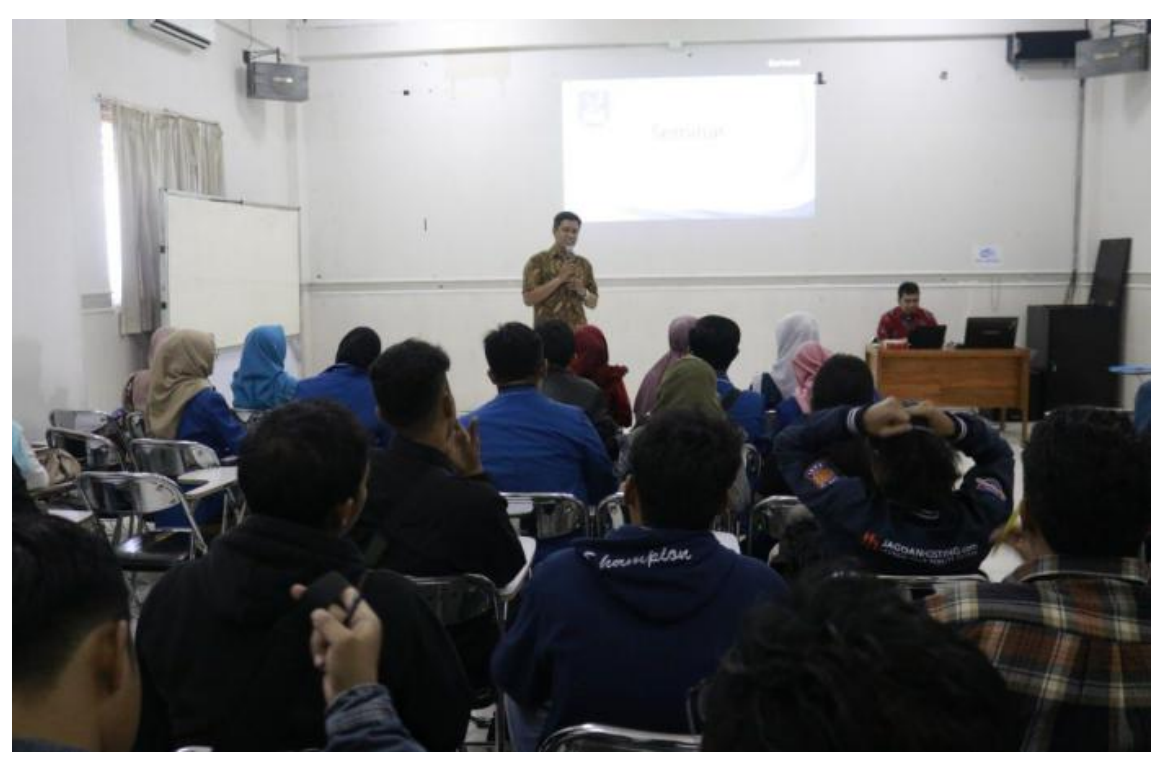

\section{Gambar 3}

\section{Sesi Tanya Jawab}

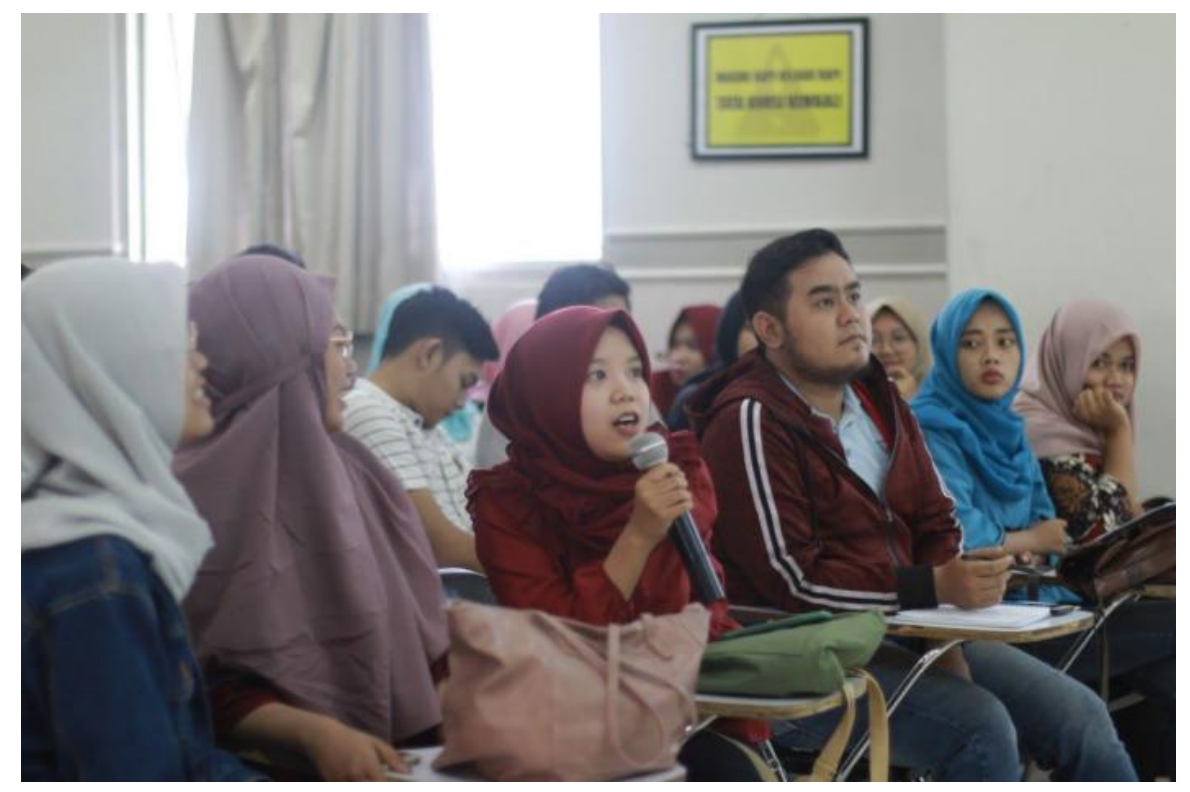




\section{Hasil}

Melalui desain kegiatan Pelatihan Empowering Digital Business bagi Pegiat Usaha Online di Kota Malang dilakukan dalam bentuk tutorial yang disampaikan secara langsung oleh pemateri, dimana berdasarkan hasil pengabdian ini, pegiat usaha online di Kota Malang sangat tertarik dan bersemangat untuk mengikuti kegiatan serupa untuk pengembangan ilmu bisnis mereka.

\section{Diskusi}

Pelatihan ini kami pandang penting karena bagaimanapun pelatihan dan pendidikan masih punya peran penting bagi perkembangan diri seorang pelaku usaha (Morrish, 2011). Memang masih terjadi perdebatan tentang bagaimana wirausaha sebenarnya, terlahir sebagai wirausaha atau belajar menjadi wirausaha (Gouveia, Dinis, do, Ferreira, \& Raposo, 2012). Namun terlepas perdebatan di atas, secara garis besar, Digital Entrepreneurship berperan penting karena terbukti bisa meningkatkan pendapatan per kapita dari sebuah negara, semakin banyak lapangan pekerjaan sebagai akibat dari digital entrepreneurship yang berkembang di negara tersebut (Zhao, Fang; Collier, 2017).

Dengan diberikannya materi Inbound Marketing, diharapkan peserta pelatihan bisa lebih siap, lebih bisa dan mau bergerak menjalankan usahanya. Disaat yang sama, kami juga menyadari bahwa sebuah pelatihan tidak bisa berdiri sendiri dalam mempersiapkan wirausaha dalam berbisnis, (Viviers, Solomon, \& Venter, 2013) mengatakan bahwa dukungan fisik seperti platform akses jaringan yang memadai dan akses ke mekanisme pendanaan bisnis kecil juga dibutuhkan agar ekosistem yang baik bagi wirausaha bisa terbentuk.

\section{Kesimpulan}

Bahwa pelatihan Inbound Marketing berdampak bagi peserta pelatihan. Hal ini bisa dilihat dari jumlah peserta, respon peserta dan banyaknya pertanyaan yang diajukan ketika pelatihan itu dijalankan.

\section{Pengakuan/Acknowledgements}

Ucapan terima kasih kami haturkan kepada pihak-pihak yang sudah membantu mensukseskan kegiatan program pengabdian masyarakat ini. Kepada anggota tim dosen pengabdian masyarakat, mahasiswa panitia, pihak kampus Institut Asia Malang, dan tentunya pihak Telkomsel, khususnya kepada pemateri, Bapak Syaiful Islam yang sudah meluangkan waktunya untuk berbagi pengetahuan, informasi dan pengalaman kepada peserta pelatihan, dan kepada pihak-pihak yang 
tidak bisa kami sebutkan satu persatu, yang ikut membantu sehingga pelatihan ini lancar

\section{Daftar Referensi}

Gouveia, R., Dinis, A., do, A., Ferreira, J., \& Raposo, M. (2012). The Effect of an Entrepreneurial Training Programme on Entrepreneurial Traits and Intention of Secondary Students. Entrepreneurship - Born, Made and Educated, (March). https://doi.org/10.5772/35302

Morrish, S. C. (2011). Entrepreneurial marketing: A strategy for the twenty-first century? Journal of Research in Marketing and Entrepreneurship, 13(2), 110119. https://doi.org/10.1108/14715201111176390

Viviers, S., Solomon, G., \& Venter, C. (2013). Entrepreneurial intentions and behaviours of South African University Students. The Southern African Journal of Entrepreneurship and Small Business Management, 6(1), 1. https://doi.org/10.4102/sajesbm.v6i1.30

Zhao, Fang; Collier, A. (2017). Digital Entrepreneurship: Research and Practice (PDF Download Available). 9th Annual Conference of the EuroMed Academy of Business, (September), 2173-2182. Retrieved from https://www.researchgate.net/publication/309242001_Digital_Entrepreneurship_ Research_and_Practice 